The research program of the Center for Economic Studies (CES) produces a wide range of theoretical and empirical economic analyses that serve to improve the statistical programs of the U.S. Bureau of the Census. Many of these analyses take the form of CES research papers. The papers are intended to make the results of CES research available to economists and other interested parties in order to encourage discussion and obtain suggestions for revision before publication. The papers are unofficial and have not undergone the review accorded official census Bureau publications. The opinions and conclusions expressed in the papers are those of the authors and do not necessarily represent those of the U.S. Bureau of the Census. Republication in whole or part must be cleared with the authors.

\title{
AGGLOMERATION, ENTERPRISE SIZE, AND PRODUCTIVITY
}

\author{
by
}

Edward J. Feser *

University of North Carolina at Chapel Hill

CES 04-15 August, 2004

All papers are screened to ensure that they do not disclose confidential information. Persons who wish to obtain a copy of the paper, submit comments about the paper, or obtain general information about the series should contact Sang $V$. Nguyen, Editor, Discussion Papers, Center for Economic Studies, Washington Plaza II, Room 206, Bureau of the Census, Washington, DC 20233-6300, (301-763-1882) or INTERNET address snguyen@ces.census.gov. 


\title{
Agglomeration, enterprise size, and productivity
}

Prepared for the "Theories of regional development: Lessons for policies of regional economic renewal and growth" workshop, 14-16 June, 1998, Uddevalla, Sweden

\author{
Edward J. Feser \\ Assistant Professor \\ Department of City and Regional Planning \\ University of North Carolina at Chapel Hill \\ CB 3140, New East Building \\ Chapel Hill, NC 27599-3140 \\ Voice: 919.962.4768 Fax: 919.962.5206 \\ E-Mail: feser@email.unc.edu
}

March 1999 


\section{Agglomeration, Enterprise Size, and Productivity ${ }^{1}$}

\section{Introduction}

Much research on agglomeration economies, and particularly recent work that builds on Marshall's concept of the industrial district, postulates that benefits derived from proximity between businesses are strongest for small enterprises (Humphrey 1995, Sweeney and Feser 1998). With internal economies a function of the shape of the average cost curve and level of production, and external economies in shifts of that curve, a small firm enjoying external economies characteristic of industrial districts (or complexes or simply urbanized areas) may face the same average costs as the larger firm producing a higher volume of output (Oughton and Whittam 1997; Carlsson 1996; Humphrey 1995). Thus we observe the seeming paradox of large firms that enjoy internal economies of scale co-existing with smaller enterprises that should, by all accounts, be operating below minimum efficient scale. With the Birch-inspired debate on the relative job- and innovation-generating capacity of small and large firms abating (Ettlinger 1997), research on the small firm sector has shifted to an examination of the business strategies and sources of competitiveness of small enterprises (e.g., Pratten 1991, Nooteboom 1993). Technological external scale economies are a key feature of this research (Oughton and Whittam 1997).

One argument is that smaller firms utilize superior flexibility and innovativeness to compete with larger producers. Borrowing from Stigler's (1951) model of market size and industry structure, Scott (1988) argues that changing market conditions favor the vertical disintegration of larger producers and the greater utilization of outsourcing. Though Stigler (1951) emphasized that growth in the size of the market makes disintegration possible, Scott considers uncertainty in demand and growing sophistication of consumers as favoring a more 
flexible, vertically disintegrated production regime. Since greater outsourcing puts pressure on the management of external transactions, business partners are encouraged to seek proximate locations. The result is a re-agglomeration of economic activity with the shift toward more flexible production modes. Pratten's (1991) study of small firms would seem to lend some credence to this scenario. He found that small firms co-exist with larger ones because the former serve market niches appropriate for their scale of production. As Carlsson (1996) notes, Pratten's study suggests that there is, in effect, a division of labor between the two types of producers, one that shows signs of being characterized as much by complementarity as competitiveness.

None of this suggests that only small firms will benefit from local externalities. Under the Scott framework, larger firms gain economies of scope and scale by outsourcing certain functions once the market is sufficient to support the independent production of those functions (giving rise to de facto externalities). Urban or industry scale might be sufficient proxies for those types of effects, provided demand is localized. Likewise, both large and small firms would be expected to benefit from other types of external economies associated with interfirm proximity, including a network of suppliers, pools of skilled labor, and knowledge spillovers, though small firms may depend to a greater degree on such advantages.

In this paper, I examine the degree to which local business externalities differ in magnitude and type among large and small enterprises in two U.S. manufacturing sectors (farm and garden machinery, SIC 352, and measuring and controlling devices, SIC 382). I begin by specifying a four factor micro-level production function with oft-cited sources of agglomeration economies (local input supply, labor pools, knowledge spillovers) treated as technology parameters. The inclusion of dummy variables representing varying definitions of plant size (and type, i.e., single or multi establishment unit) permit an investigation of differences in output elasticities indicating the 
magnitude of any agglomeration economies or spillovers for small versus large plants.

\section{A test for local external economies among small and large firms}

To determine the influence of interfirm proximity on production efficiency, I assume that plant-level manufacturing activity may be described by the following four factor function:

$$
Y_{i}=f\left(K_{i}, L_{i}, E_{i}, M_{i}, A_{i m} \ldots A_{i n}\right)
$$

where $Y, K, L, E$, and $M$ are output, capital, labor, energy, and materials, respectively, and $A_{m}(\mathrm{~m}$, ...,n) represent different sources of external economies affecting the level of technical efficiency across production units. The latter include proximity to input supplies, proximity to producer services, nature and size of the local labor pool, proximity to research universities, and degree of local innovative activity. Estimation of (1) is implemented for the two study sectors for 1992 utilizing the flexible translog production system outlined by Kim (1992), whereby a standard translog production function is estimated jointly with a set of non-linear cost share equations. The principal feature of the approach is that it imposes fewer a priori restrictions on the production structure than typical production function based studies of agglomeration economies. Space constraints preclude a full exegesis of the modeling framework here; it is described in full in Feser (1997).

To test whether geographic proximity influences efficiency differently for small versus large and branch versus single establishment enterprises, two dichotomous variables are included in the basic production function and interacted with the proximity measures. The first, SINGLE, takes a value of one if the plant is a single establishment firm and zero otherwise. The second, $S M A L L$, takes a value of one if the plant employs fewer workers than a specified employment size threshold, and zero otherwise. While defining firms as 'small' or 'large' on the basis of 
employment is imperfect at best, employment is a common means of identifying small and medium sized firms in the literature and it is also the primary means of targeting small business programs in the United States. Because there is some dispute in the literature over what constitutes a small firm (see, for example, Harrison 1994), I tested three definitions of "small" based on the first, second, and third sample quartiles for each industry. Those quartiles are 13, 27, and 70 for the farm and garden machinery sample and 15, 31, and 88 for the measuring and controlling devices sample. The third sample quartile roughly corresponds with the standard adopted by the OECD (at 100 workers) in studies of the small firm sector. Of course, any threshold is arbitrary. In the absence of better theory, the comparison of alternative standards is more informative than the use of any single definition.

\subsection{Input and proximity measures}

The estimated model includes four basic sets of variables: conventional inputs, measures of enterprise proximity, controls, and indicators of plant size and type. The construction of the conventional inputs $(K, L, E, M)$, output $(Y)$, and cost shares $\left(S_{k}, S_{l}, S_{e}, S_{m}\right)$ is described in detail in Feser (1997) as well as a technical appendix available upon request. The principal data source for the conventional input measures is the Longitudinal Research Database (LRD) of the U.S. Census. The LRD contains confidential plant-level data from the yearly Survey of Manufactures and quincentennial Census of Manufactures.

The sources of local business externalities are based on Marshall's (1961) analysis of industrial districts: availability of inputs (including manufactured inputs and producer services), the presence of specialized labor pools, and knowledge spillovers. Where appropriate, each variable is constructed to take explicit account of industry mix (i.e., the specific types of inputs and services typically utilized by study industry firms), relative demand (i.e., the importance of 
particular inputs, services, and labor in the production process), and proximity (weighted distance between enterprises using alternative decay specifications). The knowledge spillover variables are designed to measure the spatial influence of innovation activity and public knowledge infrastructure (research universities). In sum, the proximity measures embody a number of plausible assumptions derived from available theory. Although they are undoubtedly imperfect in many respects, they represent reasonable first attempts to detect subtle effects that are easily missed by simpler measures.

Local manufactured inputs and producer services. The measures of the availability of local manufactured inputs and producer services utilize a income/agglomeration potential framework. Each plant $i$ in industry $k$ purchases intermediate inputs from $p(p, \ldots, q)$ industries with plants located at points $j$. The share of total intermediate input purchases by plant $i$ in industry $k$ from each supplier industry $p$ is given by $r_{k p}$. Then, a measure of total potential intermediate input supply in the region surrounding plant $i\left(A_{T, i}\right)$ that accounts for the distance between plant $i$ and sources of supply, the size of sources of supply, and the relative mix of inputs available to plant $i$, is given by the index

$$
A_{T, i}=\sum_{p} \sum_{j} E_{p, j} h_{i j} r_{k p}
$$

where $E_{p, j}$ is employment in industry $p$ at point $j$. The factor $h_{i j}$ is the distance between plant $i$ and sources $j$ specified in the general decay form:

$$
h_{i j}=\left(m-d_{i j}\right) /\left(m-\alpha d_{i j}\right)
$$

where $m$ is the maximum allowable distance and alpha is the decay parameter. As $\alpha$ approaches 
minus infinity, $h_{i j}$ resembles the simple inverse of distance.

Note that (2) assumes that a given plant in industry $k$ purchases the same relative mix of inputs as the average in its industry. A measure of producer services availability, $A_{S, i}$, may be derived analogously, where the $E_{p, j}$ refer to employment at points $j$ for $p$ producer services sectors.

To implement $A_{T, i}$ and $A_{S, i}$, an appropriate distance measure and an assumption about the form of decay over some relevant distance are required, in addition to spatially and sectorally disaggregated data on industry size and data on input purchasing patterns. Assuming that each establishment is located at the centroid of its county, the primary measure of size $\left(E_{p, j}\right)$, where $j$ is the county centroid, is employment as reported in 1992 County Business Patterns (CBP). ${ }^{2}$ Great circle arc distances between counties are used as weights, with distance decaying slowly at first and then more rapidly up to a maximum distance of fifty miles (beyond which the distance weight falls to zero). Fifty miles was selected since transportation studies have shown that very little commuting occurs beyond this distance. The $r_{k p}$ are derived from the 1987 Benchmark InputOutput Accounts of the United States, released by the Bureau of Economic Analysis in 1994.

The adopted decay profile (Figure 1), which is generated by setting alpha equal to 0.75 , simply represents one plausible specification of the distance-related intensity of interaction likely among neighboring enterprises. ${ }^{3}$ Feser (1997) describes results of the basic model without firm size/type effects under alternative distance decays but without size/type effects. The use of alternative decays effectively provides useful information about the relative spatial influence of alternative proximity factors. But as a practical matter, comparing size/type effects and different decay specifications multiplies significantly the number of models and estimated parameters that require interpretation. Such an exercise would constitute a separate study in itself. The problem 
points to the need for further studies of business externalities that specify the decay as an inherent part of the model, rather than as an initial assumption that must be subjected later to detailed sensitivity tests.

Local manufacturing demand. The measuring and controlling devices industry is itself a key supplier to a wide range of final market manufacturing industries, from aerospace (aircraft, missiles, and space vehicles) to industrial and home appliances (refrigeration and heating equipment, electric housewares and fans, and household refrigerators and freezers). Just as manufacturers may derive benefits from proximate location to their own suppliers, they may also benefit from proximity to their major customers. To test this conjecture a demand-side proximity variable for plant $i$ in SIC 382 is included, $A_{D, i}$, that is constructed in a similar fashion to the intermediate input and producer services supply variables.

Specialized labor pool. According to Marshall, in an industrial district mutual learning takes place through a concentration of workers engaged in similar tasks, "a habit of responsibility, of carefulness and promptitude in handling expensive machinery and materials becomes the common property of all (Marshall 1961, p. 205)." To construct a labor pool variable that measures the specialized skill base of each study plant's location, I first grouped national 3-digit SIC industries into clusters based on similarities in occupational staffing patterns. Those clusters were then used to create a labor market specialization variable specific to each study plant's fifty mile location shed. Although ideally industries would be grouped together based on similar worker skill needs, detailed occupation may serve as a reasonable proxy.

The Occupational Employment Survey conducted every three years by the Bureau of Labor Statistics reports the number of workers employed in 400 occupations for each 3-digit manufacturing sector. Each column in this 400 x 140 data matrix represents the labor 
requirements vector-in terms of detailed occupation—for a specific manufacturing sector. A form of oblique factor analysis was performed on the matrix to reduce the number of columns (or variables) to a set of principal components. The method is typically used to reduce to a manageable number a large number of closely related variables. Here it is used to divide industries (the variables) into mutually exclusive groups that may be interpreted as sharing similar labor force requirements.

The procedure reduced the 140 industries to 24 clusters. SIC 352 was assigned to a cluster with 19 other industries, while SIC 382 was joined with 5 other industries. Those "labor requirements" clusters represent groups of industries that arguably employ and draw from a joint worker pool. Cities and regions specialized in a particular cluster's industries are therefore where cluster members are likely to enjoy the most significant labor pooling economies. Given $p$ cluster industries, a measure of labor specialization in the fifty mile shed surrounding plant $i$ in a given study industry is defined as:

$$
A_{R, i}=\frac{\sum_{p} \sum_{j} \frac{E_{p j} / E_{j, m}}{E_{p} / E_{m}} h_{i j}}{\sum_{j} h_{i j}}, \quad h_{i j}=1 \text { if } d_{i j} \leq 50, \text { otherwise } h_{i j}=0
$$

where $E_{p j}$ is employment in industry $p$ at location $j, E_{j, m}$ is total manufacturing employment at location $j, E_{p}$ is U.S. employment in industry $p, E_{m}$ is total U.S. manufacturing employment, and $h_{i j}$ is a zero-one indicator variable based on the distance, $d_{i j}$, between county centroids. Equation (4) is simply a location quotient averaged across cluster industries for each fifty mile commuting or activity shed. Since the variable does not account for regional differences in educational quality, the share of the population 25 years old and older with some college education (ATTAIN) is included in the model as well. The variable is calculated for all counties with centroids in plant 
i's 50 mile shed.

Innovative activity and knowledge infrastructure. Knowledge spillovers are expected to be most prevalent in locations with high rates of public and private sector innovation. A public sector innovation rate for plant $i$ 's location is defined as:

$$
A_{U, i}=\sum_{j} U_{j} h_{i j}
$$

where $U_{j}$ is total research expenditures by universities in location $j$ and $h_{i j}$ is distance between the locations $i$ and $j$, specified in hyperbolic decay form. As before, locations are defined on the basis of county centroids. Data for $U_{j}$ (628 doctoral granting institutions in 1993) are from the National Science Foundation's 1993 Survey of Scientific and Engineering Expenditures at Universities and Colleges. Only the research disciplines most relevant to the study industries are included in the expenditure figures. ${ }^{4}$

The degree of private sector innovative activity at plant $i$ 's location, $A_{P, i}$ is measured by the number of utility patents granted to residents, per capita, in the plant's fifty mile shed. U.S. patent grants by county are from the U.S. Patent and Trademark Office. Those data represent the most geographically disaggregated information on patenting activity available at the time of the study. Because of the way they are reported (residence of the first named inventor and undistinguished by patent class) $A_{P, i}$ is only a broad indicator of real inventive activity in particular localities. It is, nevertheless, an improvement over other possible alternatives, including employment in high technology sectors or state-level private sector research and development expenditures.

\subsection{Controls}

The control for educational attainment has already been noted. Two additional controls 
are included in the model: the competitive structure of local industry and a proxy for urban diseconomies. The former is based on Chinitz's (1961) hypothesis that external economies may be most prevalent in places less dominated by a few large producers. The degree to which industry in plant $i$ 's location is competitively organized, CRATIO, is defined as the share of total manufacturing sales made by the four largest firms in the plant's commuter zone. (Sales by firm are from the LRD.) Commuting zones, first created by the U.S. Department of Agriculture's Economic Research Service in 1980 and updated in 1990, constitute mutually exclusive groups of counties defined on the basis of Census journey-to-work data. To ensure that the proximity indicators do not indirectly measure generalized disadvantages associated with dense, urban places, a population density variable is included to control for possible congestion effects and other urban diseconomies. The variable, DENSITY, is defined as the number of persons per square mile in plant $i$ 's 50 mile shed (population figures are from the Bureau of Economic Analysis).

\subsection{Descriptive statistics}

Table 1 lists the model variables, along with means and standard deviations. ${ }^{5}$ The SIC 352 and 382 samples are comprised of 863 and 2,609 observations, respectively. Due to data limitations, the overall establishment size distributions of those samples do not match the population distributions for the two sectors. Each census year, to reporting burdens, the Census Bureau exempts from filing requirements a significant number of the smaller enterprises in its sampling frame (most affected businesses employ 1-2 workers, although some may employ as many as five workers). For the purposes of the preparation of summary published reports, data for those establishments are imputed and are therefore of questionable quality for micro-level analyses. Since the validity of the translog production function depends strongly on the quality of 
the underlying data, administrative records are excluded from this study. The exclusion of the smallest enterprises is important for the interpretation of the firm size findings, particularly their external validity to the industries a whole. Yet there are still many small manufacturers in the samples; one-quarter of enterprises in the SIC 352 and 382 samples employ fewer than 13 and 15 workers, respectively.

\section{$3 \quad$ Estimation and results}

To generate estimates of the link between enterprise proximity and productivity, a fully specified translog production system excluding plant size and type variables was first estimated jointly using iterated seemingly unrelated regressions (IZEF), a maximum likelihood-equivalent procedure (stage 1). After eliminating insignificant controls and cross-terms on the proximity factors (i.e., testing for factor augmentation and Hicks-neutrality of specific technology indicators), the revised models were re-estimated under different assumptions regarding production technology: homotheticity, homogeneity, and constant returns to scale (stage 2). Those tests suggested — though were not entirely conclusive- that constant returns are present in both sectors, particularly farm and garden machinery. To avoid imposing an overly restrictive assumption, the plant size and type variables were included and homogeneity imposed to generate the final estimates (stage 3). Homogeneity is less restrictive than constant returns yet is still more efficient (given the results) than non-homotheticity.

The final revised production function for SIC 352 is written as: 


$$
\begin{aligned}
\ln Y= & \alpha_{0}+\alpha_{k} \ln K+\alpha_{l} \ln L+\alpha_{e} \ln E+\alpha_{m} \ln M+\zeta \ln D E N S I T Y+\kappa \ln A T T A I N+\frac{1}{2} \beta_{k k}(\ln K)^{2}+\beta_{k l} \ln K \ln L \\
& \beta_{k e} \ln K \ln E+\beta_{k m} \ln K \ln M+\frac{1}{2} \beta_{l l}(\ln L)^{2}+\beta_{l e} \ln L \ln E+\beta_{l m} \ln L \ln M+\frac{1}{2} \beta_{e e}(\ln E)^{2}+\beta_{e m} \ln E \ln M+ \\
& \frac{1}{2} \beta_{m m}(\ln M)^{2}+\xi \ln A_{T}+\xi_{s} \ln A_{S}+\gamma_{k s} \ln A_{S} \ln K+\gamma_{l s} \ln A_{S} \ln L+\gamma_{e s} \ln A_{S} \ln E+\gamma_{m s} \ln A_{S} \ln M+\xi_{r} \ln A_{R}+ \\
& \xi_{u} \ln U+\xi_{p} \ln A_{P}+\gamma_{k p} \ln A_{P} \ln K+\gamma_{l p} A_{P} \ln L+\gamma_{e p} \ln A_{P} \ln E+\gamma_{m p} \ln A_{P} \ln M+\lambda_{f} S I N G L E+ \\
& \lambda_{t f} S I N G L E \ln A_{T}+\lambda_{s f} S I N G L E \ln A_{S}+\lambda_{r f} S I N G L E \ln A_{R}+\lambda_{u f} S I N G L E \ln A_{U}+\lambda_{p f} S I N G L E \ln A_{P}+ \\
& \lambda_{z} S M A L L+\lambda_{t z} S M A L L \ln A_{T}+\lambda_{s z} S M A L L \ln A_{S}+\lambda_{r z} S M A L L \ln A_{R}+\lambda_{u z} S M A L L \ln A_{U}+ \\
& \lambda_{p z} S M A L L \ln A_{P}+\varepsilon
\end{aligned}
$$

while the revised function for SIC 382 is:

$$
\begin{aligned}
\ln Y= & \alpha_{0}+\alpha_{k} \ln K+\alpha_{l} \ln L+\alpha_{e} \ln E+\alpha_{m} \ln M+\imath \ln C R A T I O+\kappa \ln A T T A I N+\frac{1}{2} \beta_{k z}(\ln K)^{2}+\beta_{k l} \ln K \ln L+ \\
& \beta_{k e} \ln K \ln E+\beta_{k m} \ln K \ln M+\frac{1}{2} \beta_{l l}(\ln L)^{2}+\beta_{l e} \ln L \ln E+\beta_{l m} \ln L \ln M+\frac{1}{2} \beta_{e e}(\ln E)^{2}+\beta_{e m} \ln E \ln M+ \\
& \frac{1}{2} \beta_{m m}(\ln M)^{2}+\xi_{l} \ln A_{T}+\xi_{s} \ln A_{S}+\xi_{r} \ln A_{R}+\gamma_{k r} \ln A_{R} \ln K+\gamma_{l r} \ln A_{R} \ln L+\gamma_{e r} \ln A_{R} \ln E+\gamma_{m r} \ln A_{R} \ln M \\
& \xi_{u} \ln U+\gamma_{k u} \ln A_{U} \ln K+\gamma_{l u} \ln A_{U} \ln L+\gamma_{e u} \ln A_{U} \ln E+\gamma_{\mu} \ln A_{U} \ln M+\xi_{p} \ln A_{P}+\gamma_{k p} \ln A_{P} \ln K+ \\
& \gamma_{l p} A_{P} \ln L+\gamma_{e p} \ln A_{P} \ln E+\gamma_{m p} \ln A_{P} \ln M+\xi_{d} \ln A_{D}+\lambda_{f} S I N G L E+\lambda_{t f} S I N G L E \ln A_{T}+ \\
& \lambda_{s f} S I N G L E \ln A_{S}+\lambda_{r f} S I N G L E \ln A_{R}+\lambda_{u f f} S I N G L E \ln A_{U}+\lambda_{p f} S I N G L E \ln A_{P}+\lambda_{d f} S I N G L E \ln A_{D}+ \\
& \lambda_{z} S M A L L+\lambda_{t z} S M A L L \ln A_{T}+\lambda_{s z} S M A L L \ln A_{S}+\lambda_{r z} S M A L L \ln A_{R}+\lambda_{u z} S M A L L \ln A_{U}+ \\
& \lambda_{p z} S M A L L \ln A_{P}+\lambda_{d z} S M A L L \ln A_{D}+\varepsilon
\end{aligned}
$$

Parameter estimates of the revised production functions along with asymptotic standard errors for the second quartile enterprise size specifications are reported in Tables 2 and 3. Note that in the case of the farm and garden machinery sample, there was no evidence in early stage regressions that the degree to which local industry is competitively organized determines productivity differentials among manufacturers in the industry. CRATIO, or the share of area sales held by the largest four local manufacturing firms, was consistently highly insignificant across all earlier estimated models and therefore does not appear in the revised models reported in 
Table 2. Likewise, the highly insignificant population density variable (DENSITY) was eliminated in the course of earlier SIC 382 model revisions. All early-stage models are reported in Feser (1997).

For the farm and garden machinery industry, educational attainment (ATTAIN) and population density (DENSITY) do appear to influence productivity. Plants located in denser urban environments, other things equal, tend to be less efficient — an indication that urban diseconomies are binding for this industry. Surprisingly, in the revised model excluding size/type effects, a doubling of the share of population 25 and over with some college education reduces output by 13 percent, holding all else constant (impact varies from 13 to 15 percent in the models reported in Table 2). A possible explanation for this finding is that the farm and garden machinery producer located in a region with a better educated workforce must pay a wage premium for comparably skilled workers.

In the case of measuring and controlling devices, the local four-firm concentration ratio (CRATIO) and degree of educational attainment (ATTAIN) variables are found to strongly influence productivity. Location in a region dominated by—in Chinitz's (1961) words-an “oligopolistically organized" local industrial base is associated with a significant efficiency penalty. A doubling of the local concentration ratio reduces output by approximately 13 percent, holding conventional input levels constant. On the other hand, a doubling of the rate of college attainment increases output, other things equal, of the average SIC 382 manufacturer by around 12 percent. The finding with respect to educational attainment is not particularly surprising, given the heavy dependence of this sector on a highly trained workforce.

Checking the parameters of the estimated models as reported in Tables 2 and 3, it appears that there are few statistically significant differences between small versus large plants and branch 
versus single establishments in terms of spatial economies. For SIC 352, the individual parameter estimates in Table 2 provide no evidence of significant interaction effects for any spatial variable with respect to the single/branch establishment dummies. There is only weak evidence of differences in spatial economies by firm size for the material and producer services pool variables. (The results are similar for the unreported first and third quartile plant size estimations.) When both sets of interaction terms are included in the estimated models however, the results get somewhat stronger, with most interaction effects significant with respect to plant size. The findings for SIC 382 are even weaker, suggesting few differences by plant size or type in this sector.

More easily interpreted than the parameter estimates, however, are the calculated output elasticities provided in Tables 4 and 5. Those tables, which report elasticities at the sample means, compare the sensitivity of the results to the definition of the SMALL variable. They also report the elasticities for the models excluding plant size/type effects (the overall sample estimates). Comparing the overall elasticities with those for plants of alternative sizes and types provides the best evidence of any differences in local externalities among large and small enterprises.

\subsection{Farm and garden machinery}

Looking first at the elasticities of proximity for the full sample, location in regions with high relative rates of innovation as proxied by patenting activity represents the strongest efficiency effect for the overall farm and garden machinery sample. Each doubling of the patent rate is associated with an increase in output of nearly 4 percent, holding input levels constant. At the same time, the elasticity of output with respect to proximity to university R\&D is effectively zero. A second influence on productivity among plants in the farm and garden machinery sector 
is proximity to their required mix of producer services. The magnitude of the services efficiency effect is very close to that of the patent rate. Doubling the producer services pool index increases output, other things equal, by 3.5 percent. Since the spatial variables in index form may be difficult to interpret, it is important to note that the producer services variable increases with geographic proximity, the size of the services sector, and as the mix of the services sector matches the unique requirements of the farm and garden machinery sector. Key producer services sectors for the industry are radio and television broadcasting, engineering, and advertising. The local availability of those services may allow manufacturers to outsource certain services-related functions while also enjoying face-to-face contact with suppliers.

Among the other proximity variables, the parameter on the specialized labor market variable is positive though not significant at conventional levels. Local industrial specialization in sectors using like labor does not appear to confer a productivity advantage to farm and garden machinery producers. Somewhat surprisingly, there is also no evidence that proximity to supplies of manufactured inputs is associated with greater technological efficiency. That result would seem to suggest that a farm and garden machinery plant's proximity to producers of its key intermediate inputs does not imply a higher level of efficiency, as is predicted by conventional agglomeration theory (as well as more recent contributions in industrial organization and economic geography).

How do the findings differ when controls for plant size and type are introduced? Perhaps the most significant trend in Table 4 is that across all three size definitions, economies associated with proximity to producer services are strongest for large, single establishment plants. In fact, as the definition of the small plant changes from the first to third employment quartile, the magnitude of the economy with respect to producer services increases for the large establishments. That 
may mean that access to producer services is most important for larger manufacturers that, by definition, demand more services. The service needs of smaller manufacturers may not be significant enough to make proximity to producer services suppliers a critical determinant of efficiency. In other words, perhaps the smaller manufacturers are not necessarily outsourcing services to a greater degree than their larger counterparts, as might be predicted by the flexible specialization literature. In the case of the local rate of innovation, large plants under all three definitions derive the greatest productivity advantage; indeed, there is also weak evidence of a difference between branch and single establishments, with the calculated elasticities higher for the former. Therefore, for SIC 352, the results are not uniform in one direction: small, single establishments do not necessarily benefit to a greater degree from proximity to services, inputs, and spillovers.

\subsection{Measuring and controlling devices}

The importance of some types of externalities and spillovers might be expected to be stronger for the SIC 382 sample than SIC 352. The ratio of capital to labor for the SIC 382 sample more labor-intensive manufacturing that is perhaps characterized by more customized or batch mode production. It is the customized manufacturer that is often hypothesized to depend much more strongly on spatial externalities and spillovers than the standardized producer that internalizes many important business functions. The measuring and controlling devices sector is also made up of producers that supply components to several highly technology-oriented sectors. The flexible specialization literature argues that rapid shifts in demand and markets force producers to depend to a greater degree on outsourcing for goods and services in order to maintain flexibility, and, therefore, that external economies are becoming much more prevalent in industries operating under such demand conditions. Manufacturers in SIC 382 supply industries 
such as automobiles, military weapons, guidance systems, and medical equipment that are continually innovating and introducing new products. The sector would appear to face, certainly more than the farm and garden machinery industry, the types of uncertain demand pressures described by Scott (1988) and others.

The results in Tables 3 and 5 suggest that the measuring and controlling devices plant located in a competitively organized region with a highly educated labor force, well-developed producer services, universities conducting basic research and development, and labor markets specialized in related industries is more productive, all else equal, than plants located in areas with a less favorable array of characteristics. The rate of local innovation as proxied by per capita patent grants does not influence efficiency in overall terms, although it does appear to positively augment some factors and negatively augment others. At the same time, proximity to sources of final market demand appears to negatively affect productivity; on average, the coefficient for the demand variable indicates a reduction in output of 2.4 percent for each doubling of the demand pool, holding input levels constant. Although there is a greater variety of positive spatial economies for SIC 382, the magnitudes of the individual effects tend to be smaller than those for SIC 352. For example, a doubling of the local producer services pool index is associated with an increase in output of 1.9 percent, compared with 3.5 percent for SIC 352. Proximity to producer services yields the largest effect in percentage terms for the measuring and controlling devices sector, followed by specialization in the labor market and proximity to research universities.

Finally, consider more closely the efficiency effect with respect to proximity to $R \& D$ universities. Results from the model indicate an increase in output of less than 1 percent with each doubling of the university R\&D index. Although the impact appears small, the statistical evidence with regard to this variable is among the strongest of any spatial factor. The finding, 
coupled with the efficiency effect with respect to local educational attainment, may provide some information about the nature of the impact of universities on regional economies. Given the high technology nature of the measuring and controlling devices sector, it is not surprising that scientific and engineering occupations are more common among the top fifteen occupations in this sector than in the farm and garden machinery industry. Perhaps some of the effect of the educational attainment variable may be attributed to the role of $R \& D$ universities, where most basic training of scientists and engineers takes place. On the other hand, the low magnitude of the weighted $R \& D$ variable would suggest that the university's most important role, at least for this sector, may be an educational one. That is, effectively training the next generation of workers may yield greater gains for the regional economy as opposed to conducting R\&D that might generate practical applications that improve productivity and manufacturing performance.

Overall, the results suggest spatial externalities may differ by plant type and size primarily only with respect to one variable: proximity to university R\&D. The elasticities of output with respect to university $R \& D$ reported in Table 5 are uniformly higher for small, single establishments under all three plant size definitions. For example, when small plants are defined as those with fewer than 15 employees, a doubling of the university R\&D index increases output for smaller producers by 1.4 percent, holding all conventional input levels constant. By comparison, the increase for the larger plants under that scenario is only 0.5 percent. $^{6}$ The elasticities for branch plants, particularly large branch plants, are generally near zero and statistically insignificant. There is also some evidence that diseconomies associated with proximity to sources of final market demand are strongest for smaller establishments, although the results vary by the definition of the SMALL dummy variable.

Finally, note that the models are estimated with spatial variables defined under the default 
distance decay for the study ( $\alpha=0.75$ in equation 3 ). Spatial effects may arguably manifest themselves at different spatial scales. It is possible that the plant type/size results might vary under alternative distance decay profiles; neglecting such variation could lead to false findings regarding type and size differences for specific spatial effects. Yet based on the analysis of the influence of alternative decays reported in Feser (1997), there appears to be enough consistency in the basic results across different decays, particularly in qualitative terms, to draw reasonable general conclusions about the direction and strength of any employment size/type effects.

\section{$4 \quad$ Summary and implications}

A number of theories of regional growth and change suggest that small to medium sized firms may depend on local externalities to remain competitive with larger producers. Size of firms, in most cases, is defined in employment terms. The hypothesis implies that smaller enterprises garner a more significant relative advantage from proximity to other producers than larger firms. In a micro-level test for two U.S. manufacturing sectors, this study found only weak evidence of such a dynamic, and then in the case of only one particular type of externality (knowledge spillovers).

\section{$5 \quad$ References}

Carlsson, B. 1996. Small business, flexible technology and industrial dynamics. In Small Business in the Modern Economy, edited by P. H. Admiraal, 63-125. Oxford, UK: Blackwell.

Chinitz, B. 1961. Contrasts in agglomeration: New York and Pittsburgh. American Economic Review 51: 279-89.

Ettlinger, N. 1997. An assessment of the small-firm debate in the United States. Environment and Planning A: 419-42. 
Feser, E. J. 1998a. Enterprises, external economies, and economic development. Journal of Planning Literature 12: 283-302.

Feser, E. J. 1997. The influence of business externalities and spillovers on manufacturing performance. Unpublished $\mathrm{PhD}$ dissertation, University of North Carolina at Chapel Hill.

Harrison, B. 1994. Lean and Mean. New York: Free Press.

Humphrey, J. 1995. Introduction. World Development 23: 1-7.

Kim, H. Y. 1992. The translog production function and variable returns to scale. Review of Economics and Statistics 74: 546-51.

Marshall, A. 1961. Principles of Economics: An Introductory Volume. Ninth (Variorum) Edition (1st Edition 1890). London: Macmillan.

Nooteboom, B. 1993. Firm size effects on transaction costs. Small Business Economics 5: 28395.

Oughton, C., and G. Whittam. 1997. Competition and cooperation in the small firm sector. Scottish Journal of Political Economy 44: 1-30.

Pratten, C. 1991. The Competitiveness of Small Firms. Cambridge: Cambridge University Press.

Scott, A. J. 1988. Metropolis: From the Division of Labor to Urban Form. Berkeley: University of California Press.

Stigler, G. J. 1951. The division of labour is limited by the extent of the market. Journal of Political Economy 59: 185-93.

Sweeney, S. H., and E. J. Feser. 1998. Plant size and clustering of manufacturing activity. Geographical Analysis 30: 45-64. 


\section{Notes}

1. Part of the research in this paper was conducted while the author was a research associate at the Center for Economic Studies, U.S. Bureau of the Census. Research results and conclusions expressed are those of the author and do not necessarily indicate concurrence by the Bureau of the Census or the Center for Economic Studies.

2. Where employment information is suppressed in CBP, the reported data on the number of plants in specific size categories were used to construct estimates by assuming the category's midpoint employment for each establishment.

3. A common default is the simple inverse of distance. But the inverse assumes extreme decay and all variables essentially revert to individual county-level measures.

4. Disciplines identified as relevant to the farm and garden machinery industry are mechanical engineering, industrial engineering, electrical engineering, other engineering, other physical sciences, and agricultural sciences. For the measuring and controlling devices sector, relevant disciplines are aerospace engineering, electrical engineering, mechanical engineering, industrial engineering, other engineering, astronomy, physics, other physical sciences, and computer science.

5. One legitimate question regarding the set of proximity measures is whether they measure distinct underlying concepts. In fact, no pairwise correlations among the indicators are particularly high. The correlation between the material input and producer services measures for SIC 352 is the highest at 0.70 . Moreover, most correlations are positive, as is consistent with the underlying theory. Those results suggest that not only does each factor measure a different concept, but the potential for excessive multicollinearity in the estimated model is not as extreme as might be expected given the variables' similar construction.

6. The results refer to the model with only size effects (the SMALL dummy variable) included. 
Table 1. Descriptive statistics, study industries, 1992

\begin{tabular}{llrrrr}
\hline & & \multicolumn{2}{c}{ SIC 352 (n=863) } & \multicolumn{2}{c}{ SIC 382 (n=2,609) } \\
Variable & Description & Mean & Std. Dev. & Mean & Std. Dev \\
\hline $\mathrm{Y}$ & Output (000s) & 16,667 & 74,559 & 12,553 & 36,314 \\
$\mathrm{~K}$ & Capital (000s) & 5,821 & 31,992 & 4,717 & 17,307 \\
$\mathrm{~L}$ & Labor (000s manhours) & 216 & 576 & 276 & 724 \\
$\mathrm{E}$ & Energy (million Btus) & 16,882 & 79,943 & 8,494 & 26,368 \\
$\mathrm{M}$ & Materials (000s) & 7,774 & 32,947 & 4,160 & 12,830 \\
$\mathrm{~S}_{\mathrm{k}}$ & Capital cost share & .0492 & .0246 & .0955 & .0567 \\
$\mathrm{~S}_{\mathrm{l}}$ & Labor cost share & .3882 & .1244 & .4938 & .1271 \\
$\mathrm{~S}_{\mathrm{e}}$ & Energy cost share & .0148 & .0116 & .0124 & .0106 \\
$\mathrm{~S}_{\mathrm{m}}$ & Material cost share & .5478 & .1355 & .3983 & .1400 \\
$\mathrm{~A}_{\mathrm{T}}$ & Local material pool & 455 & 806 & 3,128 & 2,775 \\
$\mathrm{~A}_{\mathrm{S}}$ & Local service pool & 2,620 & 5,808 & 15,876 & 16,953 \\
$\mathrm{~A}_{\mathrm{R}}$ & Specialized labor pool & 25.78 & 15.16 & 7.28 & 5.76 \\
$\mathrm{~A}_{\mathrm{D}}$ & Local market demand (SIC 382) & ----- & ----- & 2,659 & 3,916 \\
$\mathrm{~A}_{\mathrm{U}}$ & Proximity to R\&D universities & 7,910 & 15,501 & 60,416 & 68,200 \\
$\mathrm{~A}_{\mathrm{P}}$ & Patents per 100,000 population & 15.09 & 11.64 & 26.84 & 12.00 \\
CRATIO & 4-firm local concentration variable & .4515 & .2181 & .2663 & .1567 \\
$\mathrm{ATTAIN}$ & Share population 25+ with some college & .1747 & .0448 & .2338 & .0485 \\
DENSITY & Population per square mile & 190 & 359 & 850 & 791 \\
SMALL & 1 if establishment is 'small', 0 otherwise & ------ & ------ & ----- & ------ \\
SINGLE & 1 if plant is single estab., 0 otherwise & ----- & ----- & ----- & ------ \\
\hline
\end{tabular}

Figure 1. Distance decay specification

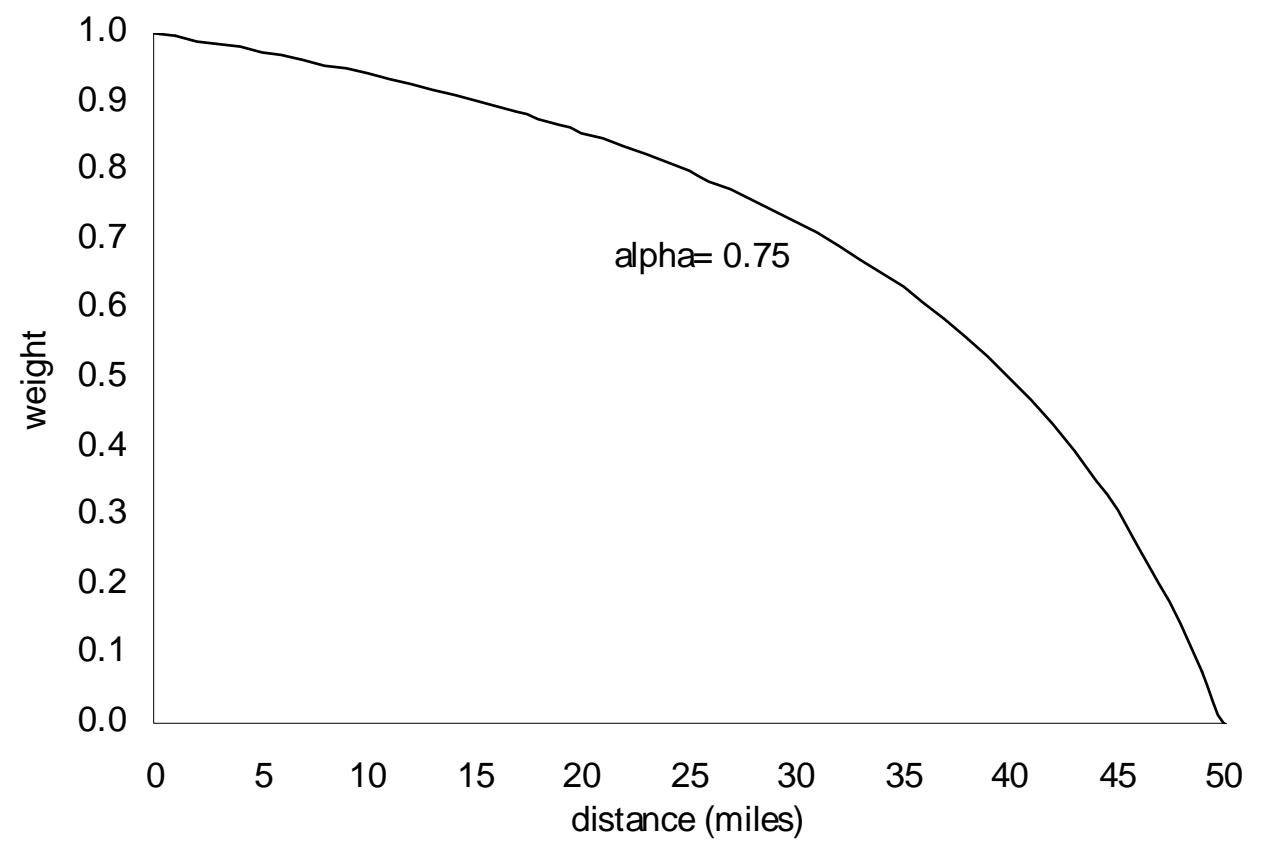


Table 2. Production function with local externalities: SIC 352

Plant type and size effects, homogeneity assumed, small plants: $<27$ employees Parameter estimates and asymptotic standard errors

\begin{tabular}{|c|c|c|c|c|c|c|c|c|c|}
\hline \multirow[b]{2}{*}{ Parameter } & \multicolumn{3}{|c|}{ Plant type effects } & \multicolumn{3}{|c|}{ Plant size effects } & \multicolumn{3}{|c|}{ Plant type and size effects } \\
\hline & Estimate & s.e. & t-statistic & Estimate & s.e. & t-statistic & Estimate & t-statistic & s.e. \\
\hline$\alpha_{0}$ & 2.0687 & 0.2575 & 8.03 & 1.5289 & 0.2436 & 6.28 & 1.7066 & 0.2865 & 5.96 \\
\hline$\alpha_{\mathrm{k}}$ & 0.0246 & 0.0025 & 9.77 & 0.0256 & 0.0026 & 9.75 & 0.0256 & 0.0026 & 9.72 \\
\hline$\alpha_{1}$ & 0.8567 & 0.0133 & 64.57 & 0.8763 & 0.0141 & 62.21 & 0.8722 & 0.0145 & 60.34 \\
\hline$\alpha_{\mathrm{m}}$ & 0.1541 & 0.0175 & 8.83 & 0.1638 & 0.0188 & 8.70 & 0.1635 & 0.0190 & 8.62 \\
\hline$\alpha_{\mathrm{e}}$ & -0.0074 & 0.0019 & -3.93 & -0.0073 & 0.0019 & -3.79 & -0.0072 & 0.0019 & -3.78 \\
\hline DENSITY & -0.0456 & 0.0230 & -1.98 & -0.0415 & 0.0230 & -1.80 & -0.0441 & 0.0231 & -1.91 \\
\hline ATTAIN & -0.1302 & 0.0646 & -2.02 & -0.1507 & 0.0643 & -2.35 & -0.1496 & 0.0646 & -2.32 \\
\hline$\beta_{\mathrm{kk}}$ & 0.0402 & 0.0006 & 65.70 & 0.0411 & 0.0007 & 61.80 & 0.0410 & 0.0007 & 60.30 \\
\hline$\beta_{\mathrm{kl}}^{\mathrm{KK}}$ & -0.0117 & 0.0006 & -19.08 & -0.0120 & 0.0006 & -19.13 & -0.0119 & 0.0006 & -19.03 \\
\hline$\beta_{\mathrm{km}}^{\mathrm{KI}}$ & -0.0286 & 0.0006 & -49.28 & -0.0292 & 0.0006 & -46.74 & -0.0291 & 0.0006 & -46.24 \\
\hline$\beta_{\mathrm{ke}}^{\mathrm{NII}}$ & 0.0001 & 0.0003 & 0.19 & 0.0001 & 0.0003 & 0.19 & 0.0001 & 0.0003 & 0.17 \\
\hline$\beta_{11}^{n c}$ & 0.1753 & 0.0034 & 51.27 & 0.1791 & 0.0035 & 50.95 & 0.1781 & 0.0036 & 49.70 \\
\hline$\beta_{1 \mathrm{~m}}$ & -0.1611 & 0.0031 & -52.40 & -0.1647 & 0.0032 & -51.96 & -0.1638 & 0.0032 & -50.67 \\
\hline$\beta_{\mathrm{le}}$ & -0.0024 & 0.0005 & -5.23 & -0.0025 & 0.0005 & -5.16 & -0.0024 & 0.0005 & -5.13 \\
\hline$\beta_{\mathrm{ee}}$ & 0.0115 & 0.0004 & 32.20 & 0.0118 & 0.0004 & 31.67 & 0.0117 & 0.0004 & 31.45 \\
\hline$\beta_{\mathrm{em}}$ & -0.0091 & 0.0004 & -21.39 & -0.0094 & 0.0004 & -21.21 & -0.0093 & 0.0004 & -21.18 \\
\hline$\beta_{\mathrm{mm}}$ & 0.1988 & 0.0030 & 66.93 & 0.2032 & 0.0031 & 65.03 & 0.2022 & 0.0032 & 62.80 \\
\hline$\xi_{\mathrm{T}}^{\mathrm{min}}$ & 0.0103 & 0.0181 & 0.57 & -0.0189 & 0.0140 & -1.35 & -0.0062 & 0.0193 & -0.32 \\
\hline$\xi_{S}$ & 0.0389 & 0.0383 & 1.02 & 0.0952 & 0.0363 & 2.62 & 0.0695 & 0.0417 & 1.67 \\
\hline$\gamma_{\mathrm{kS}}$ & -0.0002 & 0.0003 & -0.61 & -0.0003 & 0.0004 & -0.84 & -0.0003 & 0.0004 & -0.83 \\
\hline$\gamma_{1 S}$ & 0.0003 & 0.0005 & 0.66 & 0.0004 & 0.0005 & 0.84 & 0.0004 & 0.0005 & 0.82 \\
\hline$\gamma_{\mathrm{es}}$ & 0.0011 & 0.0002 & 4.69 & 0.0011 & 0.0002 & 4.52 & 0.0011 & 0.0002 & 4.51 \\
\hline$\gamma_{\mathrm{mS}}$ & -0.0043 & 0.0026 & -1.65 & -0.0055 & 0.0029 & -1.91 & -0.0055 & 0.0029 & -1.87 \\
\hline$\xi_{\mathrm{U}}$ & 0.0036 & 0.0038 & 0.96 & -0.0025 & 0.0027 & -0.91 & 0.0023 & 0.0039 & 0.59 \\
\hline$\xi_{\mathrm{P}}$ & 0.0878 & 0.0344 & 2.55 & 0.0898 & 0.0263 & 3.42 & 0.0937 & 0.0351 & 2.67 \\
\hline$\gamma_{\mathrm{kP}}$ & -0.0011 & 0.0005 & -2.07 & -0.0011 & 0.0006 & -1.99 & -0.0011 & 0.0006 & -1.99 \\
\hline$\gamma_{\mathrm{IP}}$ & 0.0139 & 0.0032 & 4.32 & 0.0135 & 0.0033 & 4.04 & 0.0135 & 0.0033 & 4.03 \\
\hline$\gamma_{\mathrm{eP}}$ & -0.0012 & 0.0004 & -2.85 & -0.0012 & 0.0004 & -2.78 & -0.0012 & 0.0004 & -2.77 \\
\hline$\gamma_{\mathrm{mP}}$ & -0.0115 & 0.0029 & -3.92 & -0.0112 & 0.0031 & -3.67 & -0.0112 & 0.0031 & -3.66 \\
\hline$\xi_{\mathrm{R}}$ & 0.0081 & 0.0320 & 0.25 & 0.0398 & 0.0229 & 1.74 & 0.0265 & 0.0335 & 0.79 \\
\hline$\lambda_{\mathrm{f}}$ & -0.1256 & 0.1857 & -0.68 & & & & -0.2225 & 0.1923 & -1.16 \\
\hline$\lambda_{\mathrm{Tf}}$ & -0.0127 & 0.0192 & -0.66 & & & & -0.0205 & 0.0202 & -1.01 \\
\hline$\lambda_{\mathrm{Uf}}$ & -0.0051 & 0.0044 & -1.16 & & & & -0.0082 & 0.0046 & -1.77 \\
\hline$\lambda_{\mathrm{Rf}}$ & 0.0050 & 0.0364 & 0.14 & & & & 0.0166 & 0.0381 & 0.43 \\
\hline$\lambda_{\mathrm{Sf}}$ & 0.0298 & 0.0293 & 1.02 & & & & 0.0446 & 0.0309 & 1.44 \\
\hline$\lambda_{\mathrm{Pf}}$ & -0.0164 & 0.0344 & -0.48 & & & & -0.0103 & 0.0370 & -0.28 \\
\hline$\lambda_{\mathrm{Z}}$ & & & & 0.4234 & 0.1626 & 2.60 & 0.4599 & 0.1690 & 2.72 \\
\hline$\lambda_{\mathrm{Tz}}$ & & & & 0.0314 & 0.0166 & 1.89 & 0.0374 & 0.0175 & 2.14 \\
\hline$\lambda_{\mathrm{Uz}}$ & & & & 0.0048 & 0.0039 & 1.25 & 0.0071 & 0.0041 & 1.75 \\
\hline$\lambda_{\mathrm{Rz}}$ & & & & -0.0447 & 0.0308 & -1.45 & -0.0455 & 0.0324 & -1.41 \\
\hline$\lambda_{\mathrm{Sz}}$ & & & & -0.0464 & 0.0253 & -1.83 & -0.0588 & 0.0267 & -2.20 \\
\hline$\lambda_{\mathrm{Pz}}^{\mathrm{NL}}$ & & & & -0.0305 & 0.0285 & -1.07 & -0.0259 & 0.0307 & -0.84 \\
\hline $\mathrm{N}$ & & 863 & & & 863 & & & 863 & \\
\hline Adj. $R^{21} s$ & Output & 0.968 & & & 0.968 & & & 0.968 & \\
\hline & K Share & 0.837 & & & 0.837 & & & 0.837 & \\
\hline & L Share & 0.711 & & & 0.711 & & & 0.711 & \\
\hline & M Share & 0.798 & & & 0.799 & & & 0.799 & \\
\hline
\end{tabular}


Table 3. Production function with local externalities: SIC 382

Plant type and size effects, homogeneity assumed, small plants: <31 employees Parameter estimates and asymptotic standard errors

\begin{tabular}{|c|c|c|c|c|c|c|c|c|c|}
\hline \multirow[b]{2}{*}{ Parameter } & \multicolumn{3}{|c|}{ Plant type effects } & \multicolumn{3}{|c|}{ Plant size effects } & \multicolumn{3}{|c|}{ Plant type and size effects } \\
\hline & Estimate & s.e. & t-statistic & Estimate & s.e. & t-statistic & Estimate & t-statistic & s.e. \\
\hline$\alpha_{0}$ & 2.8616 & 0.1141 & 25.09 & 2.7264 & 0.1080 & 25.25 & 2.8316 & 0.1213 & 23.35 \\
\hline$\alpha_{\mathrm{k}}$ & 0.0285 & 0.0037 & 7.72 & 0.0285 & 0.0037 & 7.61 & 0.0286 & 0.0037 & 7.71 \\
\hline$\alpha_{1}$ & 0.8438 & 0.0101 & 83.71 & 0.8529 & 0.0106 & 80.50 & 0.8449 & 0.0107 & 79.15 \\
\hline$\alpha_{\mathrm{m}}$ & 0.1375 & 0.0078 & 17.60 & 0.1389 & 0.0079 & 17.54 & 0.1378 & 0.0079 & 17.54 \\
\hline$\alpha_{\mathrm{e}}$ & -0.0016 & 0.0012 & -1.29 & -0.0015 & 0.0012 & -1.24 & -0.0015 & 0.0012 & -1.26 \\
\hline CRATIO & -0.1317 & 0.0467 & -2.82 & -0.1329 & 0.0468 & -2.84 & -0.1349 & 0.0468 & -2.88 \\
\hline ATTAIN & 0.1284 & 0.0346 & 3.71 & 0.1173 & 0.0346 & 3.40 & 0.1271 & 0.0347 & 3.67 \\
\hline$\beta_{\mathrm{kk}}$ & 0.0746 & 0.0008 & 99.26 & 0.0755 & 0.0008 & 93.71 & 0.0747 & 0.0008 & 91.43 \\
\hline$\beta_{\mathrm{kl}}^{\mathrm{nk}}$ & -0.0342 & 0.0008 & -42.02 & -0.0347 & 0.0008 & -42.20 & -0.0342 & 0.0008 & -41.60 \\
\hline$\beta_{\mathrm{km}}^{\mathrm{n}}$ & -0.0408 & 0.0006 & -62.90 & -0.0411 & 0.0007 & -60.24 & -0.0408 & 0.0007 & -60.03 \\
\hline$\beta_{\mathrm{ke}}^{\mathrm{nut}}$ & 0.0003 & 0.0002 & 1.45 & 0.0003 & 0.0002 & 1.44 & 0.0003 & 0.0002 & 1.43 \\
\hline$\beta_{\mathrm{ll}}^{\mathrm{Kc}}$ & 0.1693 & 0.0020 & 84.27 & 0.1714 & 0.0021 & 82.69 & 0.1694 & 0.0021 & 80.78 \\
\hline$\beta_{1 \mathrm{~m}}$ & -0.1308 & 0.0016 & -82.74 & -0.1323 & 0.0016 & -80.96 & -0.1309 & 0.0016 & -79.38 \\
\hline$\beta_{\mathrm{le}}$ & -0.0043 & 0.0003 & -15.57 & -0.0043 & 0.0003 & -15.47 & -0.0042 & 0.0003 & -15.48 \\
\hline$\beta_{\mathrm{ee}}^{\mathrm{ic}}$ & 0.0086 & 0.0002 & 39.76 & 0.0087 & 0.0002 & 39.30 & 0.0086 & 0.0002 & 39.19 \\
\hline$\beta_{\mathrm{em}}$ & -0.0047 & 0.0002 & -20.28 & -0.0047 & 0.0002 & -20.22 & -0.0047 & 0.0002 & -20.21 \\
\hline$\beta_{\mathrm{mm}}$ & 0.1762 & 0.0015 & 113.71 & 0.1782 & 0.0017 & 106.90 & 0.1764 & 0.0017 & 103.95 \\
\hline$\xi_{T}$ & 0.0156 & 0.0171 & 0.91 & 0.0106 & 0.0152 & 0.70 & 0.0193 & 0.0179 & 1.08 \\
\hline$\xi_{s}$ & 0.0181 & 0.0153 & 1.18 & 0.0119 & 0.0133 & 0.90 & 0.0149 & 0.0160 & 0.93 \\
\hline$\xi_{\mathrm{U}}$ & 0.0034 & 0.0044 & 0.78 & 0.0031 & 0.0038 & 0.80 & 0.0013 & 0.0044 & 0.30 \\
\hline$\gamma_{\mathrm{kU}}$ & -0.0001 & 0.0002 & -0.40 & -0.0001 & 0.0002 & -0.41 & -0.0001 & 0.0002 & -0.40 \\
\hline$\gamma_{\mathrm{IU}}$ & 0.0014 & 0.0005 & 2.77 & 0.0014 & 0.0005 & 2.82 & 0.0014 & 0.0005 & 2.78 \\
\hline$\dot{\gamma}_{\mathrm{eU}}$ & -0.0002 & 0.0001 & -3.29 & -0.0002 & 0.0001 & -3.31 & -0.0002 & 0.0001 & -3.29 \\
\hline$\dot{y}_{\mathrm{mU}}$ & -0.0011 & 0.0004 & -2.71 & -0.0011 & 0.0004 & -2.75 & -0.0011 & 0.0004 & -2.71 \\
\hline$\xi_{\mathrm{P}}$ & 0.0018 & 0.0257 & 0.07 & 0.0156 & 0.0234 & 0.67 & 0.0043 & 0.0264 & 0.16 \\
\hline$\gamma_{\mathrm{kP}}$ & -0.0039 & 0.0012 & -3.33 & -0.0040 & 0.0012 & -3.33 & -0.0039 & 0.0012 & -3.32 \\
\hline$\gamma_{\mathrm{IP}}$ & 0.0117 & 0.0031 & 3.78 & 0.0119 & 0.0031 & 3.79 & 0.0117 & 0.0031 & 3.77 \\
\hline$\dot{\gamma}_{\mathrm{eP}}$ & -0.0007 & 0.0004 & -1.82 & -0.0007 & 0.0004 & -1.81 & -0.0007 & 0.0004 & -1.82 \\
\hline$\dot{\gamma}_{\mathrm{mP}}$ & -0.0071 & 0.0025 & -2.80 & -0.0072 & 0.0026 & -2.81 & -0.0071 & 0.0026 & -2.78 \\
\hline$\xi_{R}$ & 0.0248 & 0.0120 & 2.06 & 0.0385 & 0.0109 & 3.55 & 0.0299 & 0.0125 & 2.39 \\
\hline$\gamma_{\mathrm{kR}}$ & -0.0009 & 0.0006 & -1.54 & -0.0009 & 0.0006 & -1.59 & -0.0009 & 0.0006 & -1.54 \\
\hline$\dot{\gamma}_{\mathrm{rR}}$ & 0.0072 & 0.0015 & 4.96 & 0.0073 & 0.0015 & 5.00 & 0.0072 & 0.0015 & 4.95 \\
\hline$\dot{\gamma}_{\mathrm{eR}}$ & 0.0013 & 0.0002 & 7.15 & 0.0013 & 0.0002 & 7.14 & 0.0013 & 0.0002 & 7.15 \\
\hline$\gamma_{m R}$ & -0.0076 & 0.0012 & -6.37 & -0.0077 & 0.0012 & -6.40 & -0.0076 & 0.0012 & -6.35 \\
\hline$\xi_{D}$ & -0.0263 & 0.0127 & -2.07 & -0.0178 & 0.0113 & -1.58 & -0.0229 & 0.0133 & -1.72 \\
\hline$\lambda_{\mathrm{f}}$ & -0.0874 & 0.1016 & -0.86 & & & & -0.0986 & 0.1098 & -0.90 \\
\hline$\lambda_{\mathrm{Tf}}$ & -0.0358 & 0.0212 & -1.69 & & & & -0.0256 & 0.0234 & -1.09 \\
\hline$\lambda_{\mathrm{Sf}}$ & 0.0026 & 0.0193 & 0.13 & & & & -0.0038 & 0.0211 & -0.18 \\
\hline$\lambda_{\mathrm{Df}}$ & 0.0054 & 0.0157 & 0.34 & & & & 0.0110 & 0.0171 & 0.64 \\
\hline$\lambda_{\text {Uf }}$ & 0.0118 & 0.0047 & 2.50 & & & & 0.0068 & 0.0053 & 1.27 \\
\hline$\lambda_{\mathrm{Pf}}$ & 0.0360 & 0.0278 & 1.29 & & & & 0.0320 & 0.0313 & 1.02 \\
\hline$\lambda_{\mathrm{Rf}}$ & 0.0048 & 0.0122 & 0.39 & & & & 0.0152 & 0.0132 & 1.16 \\
\hline$\lambda_{\mathrm{z}}$ & & & & 0.0587 & 0.1016 & 0.58 & 0.0877 & 0.1095 & 0.80 \\
\hline$\lambda_{\mathrm{Tz}}$ & & & & -0.0318 & 0.0208 & -1.53 & -0.0200 & 0.0229 & -0.87 \\
\hline$\lambda_{\mathrm{Sz}}$ & & & & 0.0099 & 0.0190 & 0.52 & 0.0114 & 0.0207 & 0.55 \\
\hline$\lambda_{\mathrm{Dz}}$ & & & & -0.0104 & 0.0154 & -0.68 & -0.0138 & 0.0167 & -0.83 \\
\hline$\lambda_{\mathrm{Uz}}$ & & & & 0.0168 & 0.0047 & 3.60 & 0.0117 & 0.0053 & 2.22 \\
\hline$\lambda_{\mathrm{Pz}}$ & & & & 0.0085 & 0.0277 & 0.31 & -0.0060 & 0.0311 & -0.19 \\
\hline$\lambda_{\mathrm{Rz}}$ & & & & -0.0168 & 0.0116 & -1.45 & -0.0216 & 0.0125 & -1.73 \\
\hline $\mathrm{N}$ & & 2609 & & & 2609 & & & 2609 & \\
\hline \multirow[t]{4}{*}{ Adj. $R^{21} s$} & Output & 0.958 & & & 0.958 & & & 0.958 & \\
\hline & K Share & 0.780 & & & 0.780 & & & 0.780 & \\
\hline & L Share & 0.691 & & & 0.691 & & & 0.691 & \\
\hline & M Share & 0.829 & & & 0.828 & & & 0.829 & \\
\hline
\end{tabular}




\begin{tabular}{|c|c|c|c|c|c|c|c|c|c|c|c|c|c|c|c|c|c|c|}
\hline \multirow[b]{2}{*}{ Proximity index } & \multicolumn{6}{|c|}{ Full Sample } & \multicolumn{4}{|c|}{ Small: $<13$ Employees } & \multicolumn{4}{|c|}{ Small: $<27$ Employees } & \multicolumn{4}{|c|}{ Small: $<70$ Employees } \\
\hline & Est. & $\mathrm{t}$-Stat. & Est. & $\mathrm{t}$-Stat. & Est. & $\mathrm{t}$-Stat. & Est. & t-Stat. & Est. & t-Stat. & Est. & t-Stat. & Est. & $\mathrm{t}$-Stat. & Est. & t-Stat. & Est. & t-Stat. \\
\hline & \multicolumn{2}{|c|}{ All } & \multicolumn{2}{|c|}{ Single } & \multicolumn{2}{|c|}{ Branch } & \multicolumn{2}{|c|}{ Small } & \multicolumn{2}{|c|}{ Large } & \multicolumn{2}{|c|}{ Small } & \multicolumn{2}{|c|}{ Large } & \multicolumn{2}{|c|}{ Small } & \multicolumn{2}{|c|}{ Large } \\
\hline \multirow{6}{*}{$\begin{array}{l}\text { Manufactured Input Pool } \\
\text { Producers Svcs Pool } \\
\text { Specialized Labor Pool } \\
\text { Research Universities } \\
\text { Local Innovation Rate }\end{array}$} & 0.000 & 0.05 & -0.002 & -0.23 & 0.010 & 0.57 & 0.026 & 1.62 & -0.009 & -0.85 & 0.012 & 1.09 & -0.019 & -1.35 & 0.005 & 0.51 & -0.018 & -0.93 \\
\hline & 0.038 & 1.89 & 0.046 & 2.16 & 0.017 & 0.56 & -0.017 & -0.59 & 0.053 & 2.48 & 0.018 & 0.76 & 0.064 & 2.62 & 0.028 & 1.34 & 0.074 & 2.30 \\
\hline & 0.013 & 0.86 & 0.013 & 0.75 & 0.008 & 0.25 & -0.010 & -0.38 & 0.026 & 1.44 & -0.005 & -0.23 & 0.040 & 1.74 & 0.004 & 0.20 & 0.047 & 1.37 \\
\hline & 0.000 & -0.02 & -0.001 & -0.65 & 0.004 & 0.96 & 0.004 & 0.94 & -0.001 & -0.53 & 0.002 & 0.86 & -0.002 & -0.91 & 0.002 & 0.79 & -0.006 & -1.53 \\
\hline & 0.035 & 2.20 & 0.030 & 1.73 & 0.047 & 1.48 & -0.016 & -0.53 & 0.045 & 2.57 & 0.019 & 0.93 & 0.050 & 2.24 & 0.030 & 1.72 & 0.047 & 1.45 \\
\hline & & & & & & & \multicolumn{2}{|c|}{ Single } & \multicolumn{2}{|c|}{ Branch } & \multicolumn{2}{|c|}{ Single } & \multicolumn{2}{|c|}{ Branch } & \multicolumn{2}{|c|}{ Single } & \multirow{2}{*}{\multicolumn{2}{|c|}{ Branch }} \\
\hline Manufactured Input Pool & & & & & & & & & & & & & & & & & & \\
\hline Small & & & & & & & 0.025 & 1.52 & 0.041 & 1.72 & 0.011 & 0.92 & 0.031 & 1.46 & 0.002 & 0.21 & 0.031 & 1.40 \\
\hline Large & & & & & & & -0.013 & -1.09 & 0.003 & 0.17 & -0.027 & -1.68 & -0.006 & -0.32 & -0.034 & -1.49 & -0.006 & -0.28 \\
\hline \multicolumn{19}{|l|}{ Producers Services Pool } \\
\hline Small & & & & & & & -0.012 & -0.41 & -0.053 & -1.39 & 0.024 & 1.04 & -0.020 & -0.58 & 0.038 & 1.73 & -0.018 & -0.54 \\
\hline Large & & & & & & & 0.067 & 2.88 & 0.026 & 0.87 & 0.083 & 3.02 & 0.039 & 1.26 & 0.107 & 2.88 & 0.051 & 1.47 \\
\hline \multicolumn{19}{|l|}{ Specialized Labor Pool } \\
\hline Small & & & & & & & -0.010 & -0.37 & -0.034 & -0.77 & -0.002 & -0.11 & -0.019 & -0.48 & 0.006 & 0.34 & -0.009 & -0.22 \\
\hline Large & & & & & & & 0.033 & 1.51 & 0.009 & 0.29 & 0.043 & 1.60 & 0.027 & 0.79 & 0.050 & 1.14 & 0.034 & 0.91 \\
\hline \multicolumn{19}{|l|}{ Research Universities } \\
\hline Small & & & & & & & 0.003 & 0.77 & 0.010 & 1.72 & 0.001 & 0.45 & 0.009 & 1.94 & 0.000 & 0.05 & 0.011 & 2.17 \\
\hline Large & & & & & & & -0.003 & -1.30 & 0.003 & 0.89 & -0.006 & -1.78 & 0.002 & 0.59 & -0.012 & -2.44 & -0.002 & -0.43 \\
\hline \multicolumn{19}{|l|}{ Local Innovation Rate } \\
\hline Small & & & & & & & -0.015 & -0.49 & 0.002 & 0.05 & 0.018 & 0.85 & 0.028 & 0.70 & 0.028 & 1.55 & 0.033 & 0.77 \\
\hline Large & & & & & & & 0.039 & 1.96 & 0.056 & 1.77 & 0.044 & 1.66 & 0.054 & 1.68 & 0.042 & 0.96 & 0.047 & 1.34 \\
\hline
\end{tabular}

Note: Elasticities are evaluated at sample means.

Table 5. Output elasticities by plant type and size, measuring and controlling devices, estimates and asymptotic t-statistics

\begin{tabular}{|c|c|c|c|c|c|c|c|c|c|c|c|c|c|c|c|c|c|c|}
\hline \multirow[b]{2}{*}{ Externality/Spillovers } & & & & & & & \multicolumn{4}{|c|}{ Small: $<15$ Employees } & \multicolumn{4}{|c|}{ Small: $<31$ Employees } & \multicolumn{4}{|c|}{ Small: $<88$ Employees } \\
\hline & & & & & & & Est. & t-Stat. & Est. & $\mathrm{t}$-Stat. & Est. & t-Stat. & Est. & t-Stat. & Est. & t-Stat. & Est. & t-Stat. \\
\hline \multirow{8}{*}{$\begin{array}{l}\text { Manufactured Input Pool } \\
\text { Producers Svcs Pool } \\
\text { Specialized Labor Pool } \\
\text { Local Demand Pool } \\
\text { Research Universities } \\
\text { Local Innovation Rate }\end{array}$} & \multicolumn{2}{|c|}{ All } & \multicolumn{2}{|c|}{ Single } & \multicolumn{2}{|c|}{ Branch } & \multicolumn{2}{|c|}{ Small } & \multicolumn{2}{|c|}{ Large } & \multicolumn{2}{|c|}{ Small } & \multicolumn{2}{|c|}{ Large } & \multicolumn{2}{|c|}{ Small } & \multicolumn{2}{|c|}{ Large } \\
\hline & -0.006 & -0.49 & -0.02 & -1.43 & 0.016 & 0.91 & -0.023 & -1.04 & 0.001 & 0.04 & -0.021 & -1.35 & 0.011 & 0.70 & -0.006 & -0.45 & -0.005 & -0.22 \\
\hline & 0.019 & 1.88 & 0.021 & 1.64 & 0.018 & 1.18 & 0.015 & 0.79 & 0.019 & 1.63 & 0.022 & 1.53 & 0.012 & 0.90 & 0.022 & 1.86 & 0.013 & 0.68 \\
\hline & 0.013 & 1.86 & 0.013 & 1.65 & 0.008 & 0.79 & 0.016 & 1.36 & 0.013 & 1.62 & 0.005 & 0.57 & 0.022 & 2.36 & 0.009 & 1.24 & 0.024 & 1.72 \\
\hline & -0.023 & -2.75 & -0.021 & -2.00 & -0.026 & -2.07 & -0.026 & -1.69 & -0.022 & -2.28 & -0.028 & -2.45 & -0.018 & -1.58 & -0.025 & -2.65 & -0.018 & -1.13 \\
\hline & 0.007 & 2.78 & 0.012 & 3.76 & 0.000 & -0.01 & 0.014 & 2.83 & 0.005 & 1.69 & 0.016 & 4.48 & 0.000 & -0.13 & 0.008 & 2.83 & 0.004 & 0.76 \\
\hline & -0.006 & -0.38 & 0.01 & 0.48 & -0.03 & -1.19 & 0.003 & 0.10 & -0.010 & -0.58 & -0.005 & -0.23 & -0.013 & -0.67 & 0.002 & 0.10 & -0.027 & -0.98 \\
\hline & & & & & & & \multicolumn{2}{|c|}{ Single } & \multicolumn{2}{|c|}{ Branch } & \multicolumn{2}{|c|}{ Single } & \multicolumn{2}{|c|}{ Branch } & \multicolumn{2}{|c|}{ Single } & \multicolumn{2}{|c|}{ Branch } \\
\hline Manufactured Input Pool & & & & & & & & & & & & & & & & & & \\
\hline Small & & & & & & & -0.028 & -1.24 & 0.005 & 0.18 & -0.026 & -1.62 & -0.001 & -0.03 & -0.018 & -1.21 & 0.023 & 1.08 \\
\hline \multirow{2}{*}{\multicolumn{19}{|c|}{$\begin{array}{l}\text { Large } \\
\text { Producers Services Pool }\end{array}$}} \\
\hline & & & & & & & & & & & & & & & & & & \\
\hline Small & & & & & & & 0.017 & 0.84 & 0.013 & 0.50 & 0.022 & 1.51 & 0.026 & 1.17 & 0.022 & 1.74 & 0.029 & 1.39 \\
\hline Large & & & & & & & 0.022 & 1.47 & 0.018 & 1.16 & 0.011 & 0.61 & 0.015 & 0.93 & 0.005 & 0.20 & 0.012 & 0.60 \\
\hline \multicolumn{19}{|l|}{ Specialized Labor Pool } \\
\hline Small & & & & & & & 0.016 & 1.34 & 0.011 & 0.68 & 0.007 & 0.78 & -0.008 & -0.59 & 0.011 & 1.35 & 0.000 & 0.01 \\
\hline Large & & & & & & & 0.014 & 1.46 & 0.009 & 0.82 & 0.029 & 2.48 & 0.013 & 1.21 & 0.030 & 1.79 & 0.019 & 1.34 \\
\hline \multicolumn{19}{|l|}{ Local Demand Pool } \\
\hline Small & & & & & & & -0.024 & -1.53 & -0.030 & -1.47 & -0.026 & -2.15 & -0.037 & -2.05 & -0.023 & -2.12 & -0.035 & -2.23 \\
\hline Large & & & & & & & -0.020 & -1.62 & -0.025 & -1.97 & -0.012 & -0.79 & -0.023 & -1.72 & -0.007 & -0.33 & -0.019 & -1.16 \\
\hline \multicolumn{19}{|l|}{ Research Universities } \\
\hline Small & & & & & & & 0.014 & 2.83 & 0.003 & 0.44 & 0.016 & 4.41 & 0.010 & 1.63 & 0.011 & 3.60 & -0.002 & -0.32 \\
\hline Large & & & & & & & 0.011 & 2.91 & -0.001 & -0.16 & 0.005 & 1.04 & -0.002 & -0.52 & 0.015 & 2.26 & 0.002 & 0.34 \\
\hline \multicolumn{19}{|l|}{ Local Innovation Rate } \\
\hline Small & & & & & & & 0.009 & 0.31 & -0.026 & -0.67 & 0.002 & 0.07 & -0.030 & -0.90 & 0.010 & 0.53 & -0.023 & -0.77 \\
\hline Large & & & & & & & 0.008 & 0.36 & -0.026 & -1.16 & 0.008 & 0.27 & -0.024 & -1.04 & 0.002 & 0.04 & -0.031 & -1.11 \\
\hline
\end{tabular}

